\title{
Pandemia à Portuguesa: um relato sobre o Covid-19 em Portugal
}

Pandémie à portugaise: témoignage sur le Covid-19

Pandemia à portuguesa: un informe sobre Covid-19 en Portugal

Portuguese Pandemic: an account of Covid-19 in Portugal

\section{Lucas Pacheco Campos and Tuíla Lins}

\section{(2) OpenEdition}

\section{Journals}

\section{Electronic version}

URL: http://journals.openedition.org/espacoeconomia/10369

DOI: 10.4000/espacoeconomia.10369

ISSN: 2317-7837

\section{Publisher}

Núcleo de Pesquisa Espaço \& Economia

\section{Electronic reference}

Lucas Pacheco Campos and Tuíla Lins, «Pandemia à Portuguesa: um relato sobre o Covid-19 em Portugal », Espaço e Economia [Online], 17 | 2020, Online since 06 April 2020, connection on 21 April 2020. URL : http://journals.openedition.org/espacoeconomia/10369; DOI : https://doi.org/10.4000/ espacoeconomia.10369

This text was automatically generated on 21 April 2020.

(c) NUPEE 


\title{
Pandemia à Portuguesa: um relato sobre o Covid-19 em Portugal
}

\author{
Pandémie à portugaise: témoignage sur le Covid-19 \\ Pandemia à portuguesa: un informe sobre Covid-19 en Portugal \\ Portuguese Pandemic: an account of Covid-19 in Portugal
}

Lucas Pacheco Campos and Tuíla Lins

\begin{abstract}
"Sem futuro, o presente não serve para nada, é como se não existisse.
Pode ser que a humanidade venha a conseguir viver sem olhos, mas então deixará de ser humanidade."

(José Saramago, em "Ensaio sobre a cegueira", 1995)
\end{abstract}

1 No último dia de 2019, véspera das comemorações de Ano Novo, a Organização Mundial da Saúde (OMS) era avisada pelo governo chinês sobre a existência de mais de duas dezenas de casos de uma pneumonia de origem desconhecida, detectados na cidade de Wuhan, na província de Hubei. Cerca de uma semana depois, precisamente no dia 7 de janeiro, as autoridades chinesas anunciavam ao mundo que cientistas daquele país haviam detectado a origem da doença. Tratava-se de uma nova cepa do coronavírus, grupo viral que provoca infecção no trato respiratório, podendo evoluir para quadros graves de pneumonia e até a morte. A doença derivada do novo vírus viria a ser denominada pela OMS como Covid-19, em 11 de fevereiro.

2 Se ainda é prematuro determinar a forma exata e o local onde surgiu o novo vírus hipóteses têm sido debatidas por especialistas de todo o mundo -, algo já era evidente nos primeiros dias de 2020: o alto poder de propagação entre humanos e a necessidade de atuação imediata para tentativa de contenção e/ou mitigação de sua disseminação. Em 22 de janeiro, já havia pelos menos cinco países com casos identificados: China, Estados Unidos, Japão, Coréia do Sul e Tailândia. Só na China, eram mais de 600 casos confirmados e pelo menos 17 mortos $^{1}$. Apesar do baixo percentual de letalidade naquele momento, a disseminação da nova doença se alastrava em velocidade avassaladora, ameaçando os sistemas de saúde e colocando em risco as vidas de milhões de pessoas em todo o mundo. 
O governo chinês entendeu rapidamente a gravidade da situação e iniciou um conjunto de medidas drásticas, impondo quarentena e isolamento em diversas cidades, levantando hospitais em poucos dias, mobilizando a população e organizando seu sistema produtivo e de saúde para enfrentar o que chamou de "guerra popular" contra o vírus ${ }^{2}$. Não deixa de ser curioso que o Ocidente tenha testemunhado o surgimento da nova doença em meio às tradicionais festas da virada, enquanto que, cerca de vinte dias depois, o ano novo chinês, maior evento popular daquele país, tenha sido cancelado como medida urgente para se evitar aglomerações e amortecer a disseminação da doença ${ }^{3}$.

4 A despeito do que certo discurso tem propagado, espalhando teorias conspiratórias contra o governo do Partido Comunista da China, as ações chinesas para contenção do surto em seu território são "provavelmente as mais ambiciosas, ágeis e agressivas da história". Estas palavras são de Bruce Aylward, chefe da equipe de peritos estrangeiros da OMS mobilizada para a China, afirmadas em coletiva de imprensa realizada no fim de fevereiro4. Ele declarou ainda que as acertadas medidas chinesas forneceram "algum tempo" para que os países ocidentais pudessem se preparar. Porém, advertiu que se deveria "trabalhar rápido" e que a comunidade internacional não estaria compreendendo as necessidades do momento.

5 Se a doença já havia chegado aos Estados Unidos em medos de janeiro, o primeiro caso confirmado na União Europeia (UE) foi na França, no dia 24 do mesmo mês. Menos de uma semana depois, dia 30, a OMS elevava o surto à condição de emergência para a saúde pública internacional. Os níveis de alerta quanto à gravidade e à ameaça do Covid-19 viriam a se elevar progressivamente na medida em que a quantidade de casos se espalhava pelo mundo até que, em 11 de março, a OMS declarou oficialmente a existência de uma pandemia com "níveis alarmantes de propagação" do vírus, o que foi intensificado pela "inação" da maior parte dos governos, segundo a própria organização ${ }^{5}$. Naquele momento, havia mais de 118 mil casos registrados em mais de 110 países, tendo pelo menos 4.291 mortes confirmadas, e as projeções não eram animadoras.

6 No mesmo dia, seguindo a linha de Aylward, o diretor-geral da OMS, Adhanom Ghebreyesus, elogiou as ações do governo chinês e afirmou que os demais países somente poderiam mudar o curso da pandemia em seus territórios caso se dispusessem a detectar, testar, isolar, rastrear e mobilizar as pessoas nas respostas necessárias. Em poucas palavras, enquanto a China já dava sinais de enfrentamento positivo da situação $0^{6}$, autoridades internacionais de saúde declaravam seus receios e suas advertências quanto à morosidade das ações que vinham sendo adotadas na maior parte do mundo, sobretudo no Ocidente. Cumpre agora acompanhar e analisar criticamente o que tem sido promovido e suas consequências. É uma tarefa que apenas se inicia.

7 Com o intuito de contribuir para o entendimento da nova conjuntura e das ações colocadas em prática para o enfrentamento da pandemia, este texto se propõe a fazer a um breve relato e iniciar algumas interpretações sobre a evolução das medidas adotadas em um país do sul da Europa: Portugal. A primeira razão dessa escolha se dá pela proximidade teórica e pessoal dos autores com o país, sendo o lugar de onde estão vivenciando a pandemia e seus efeitos imediatos. A segunda razão está numa característica que tem singularizado o país nesse momento. Diferente de seus vizinhos mais próximos, como Espanha e Itália, Portugal pouco tem figurado nos noticiários 
internacionais e, dentro das devidas proporções, aparenta lidar razoavelmente bem com as repostas necessárias para minimizar os efeitos da crise sanitária, conforme orientações da própria OMS.

8 Como qualquer análise feita no calor dos acontecimentos, nossos apontamentos não pretendem ser definitivos, mas adicionar elementos para auxiliar na compreensão do atual cenário. Portanto, considerando as possibilidades desse espaço, sublinha-se que o texto foca em ações do governo português e os principais desdobramentos sanitários, institucionais e econômicos ao longo de uma crise que ainda está em curso. As dimensões aqui levantadas devem ser analisadas enquanto partes um quadro maior de disputas e conflitos entre classes e interesses geopolíticos de ordem regional e, em última instância, global.

\section{Portugal em tempos de Covid-19}

Os dois primeiros casos em solo português foram confirmados apenas em 2 de março e a primeira morte viria a ocorrer duas semanas depois, no dia 16. Contudo, o governo do Partido Socialista, liderado pelo Primeiro-ministro Antônio Costa, já vinha tomando as primeiras medidas com vistas a preparar o país sanitária e institucionalmente desde o fim de janeiro, quando a Direção Geral de Saúde (DGS) colocou os hospitais de São João, no Porto, Curry Cabral e Estefânia, em Lisboa, em estado de alerta. Em fevereiro, ainda sem casos registrados, o governo anunciou reforço de $20 \%$ do estoque de medicamentos em toda o Sistema Nacional de Saúde (SNS) e a DGS divulgou orientações e regras sobre contingenciamento de casos suspeitos para empresas, portos e viajantes via marítima. No início de março, a pandemia já era pauta praticamente única em toda a mídia local. Um dos principais motivos para a preocupação é a composição etária da população, com alto percentual de idosos.

Diversas medidas, combinando contingências diretamente relacionadas ao combate no campo da saúde com outras no campo econômico, continuaram a ser tomadas tanto pelo governo nacional quanto por autoridades locais ao longo da primeira semana de março. Pode-se destacar: a criação de hospitais de campanha em Lisboa e no Porto para desafogar o SNS; a determinação de teletrabalho na Administração Pública; a determinação de que trabalhadores em quarentena receberiam integralmente seus rendimentos nos primeiros 14 dias de isolamento; a determinação de que todas as empresas e órgãos públicos deveriam estabelecer planos de contingência locais para lidar com casos suspeitos; a suspensão dos voos para todas as regiões da Itália por pelo menos 14 dias; o encerramento de universidades, museus, teatros, atividades desportivas e demais tipos de eventos por todo o país 7 . Respondendo agilmente às pressões empresariais, o governo anunciava também uma linha de crédito com valor inicial de 100 milhões de euros, elevada em seguida a 200 milhões, para apoio a empresas afetadas pelo impacto económico imediato8.

11 A partir da declaração de pandemia da OMS, em 11 de março, as medidas do Estado português para garantir o isolamento social se intensificaram sensivelmente. As escolas de todos os ciclos formativos foram fechadas a partir de 16 de março. Foi declarado estado de alerta em todo o país e as forças de saúde, proteção civil e segurança foram colocadas em prontidão. A suspensão de atividades, o encerramento de estabelecimentos e/ou a restrição de acessos se expandiram para discotecas, mercados, 
restaurantes, serviços públicos, centros comerciais, cruzeiros, aviões, praias e outros tipos de locais e eventos.

Em 16 de março, expandindo o pacote de socorro ao mercado, entrou em vigor uma medida que flexibiliza e facilita as regras para que empresas pudessem aplicar o recurso de layoff, isto é, a suspensão de contratos de trabalho'. Essa medida significa concretamente a possibilidade de redução de um terço do rendimento bruto dos trabalhadores até ao valor máximo de 1.905 euros, sendo $70 \%$ pagos pelo fundo público via recursos da Segurança Social, e 30\% pelo empregador, condição que poderá ser renovada pelas empresas por período de até seis meses. A teórica contrapartida para os trabalhadores é o compromisso dos empresários beneficiados em não realizar demissões.

Quanto aos trabalhadores autônomos, nomeadamente os chamados "recibos verdes", foi promulgado um decreto que institui apoio emergencial de até 438 euros mensais por seis meses, a serem pagos pela Segurança Social ${ }^{10}$. Outra medida que pode ser acessada por autônomos é o apoio, que varia de 438 a 1.097 euros, às famílias de trabalhadores por recibos verdes que devem ficar em casa durante o período de fechamento das escolas para acompanhar os filhos, não podendo exercer o teletrabalho ${ }^{11}$.

No que diz respeito às instituições de ensino, apesar da suspensão das aulas, muitas estão funcionando como importantes bases de apoio para uma parcela importante de famílias. Mais de 700 escolas seguem abertas para servir refeições diariamente a estudantes em situação de vulnerabilidade, bem como a filhos de trabalhadores de serviços essenciais que não podem exercer suas funções de maneira remota ${ }^{12}$.

15 As Regiões Autónomas também reforçaram medidas ao longo das duas primeiras semanas de março, impondo quarentena obrigatória a todos que chegassem às ilhas. $\mathrm{Na}$ Madeira, suspendeu-se as atracagens de cruzeiros, implementou-se a medição de temperatura dos passageiros em aeroportos, cancelou-se voos vindos de países com casos de transmissão ativa do vírus e isentou-se a população do pagamento de água e luz durante o surto no país. O governo dos Açores, por sua vez, também impôs restrições de acesso à região e fechou escolas, museus, cinemas, teatros e ginásios esportivos.

Em 18 de março, depois de intensos debates na Assembleia da República e nos meios de comunicação social, foi decretado Estado de Emergência no país pelo Presidente da República, com apoio do Primeiro-ministro e maioria de votos no Parlamento, como determina a Constituição Portuguesa. 0 decreto enrijeceu ainda mais o controle quanto ao isolamento social para todos os portugueses e residentes no país, configurando o desrespeito das novas regras como crime de desobediência civil ${ }^{13}$.

De acordo com o decreto, restringiu-se a liberdade de reunião e de circulação de pessoas em vias públicas apenas para casos como aquisição de bens ou serviços, motivos de saúde, desempenho de atividades laborais, emergências familiares e outros previstos em regulamentações promulgadas em seguida. A lista de locais e estabelecimentos encerrados ou com funcionamento restringido foi alongada. Cita-se, como exemplo, a proibição de todos os eventos religiosos que impliquem aglomerações, o que incluí qualquer tipo de culto, ritual e funeral. Foram estabelecidas regras e determinações de funcionamento dos serviços públicos e privados tidos como essenciais, tais como serviços de saúde, defesa, justiça, transportes, agricultura, pesca e energia. Determinou-se também a possibilidade de requisição civil por parte das autoridades de "quaisquer bens ou serviços de pessoas coletivas de direito público ou privado, que se 
mostrem necessários ao combate à doença Covid-19". o decreto tem duração inicial de 15 dias e está em vias de ser prorrogado.

No mesmo dia da promulgação do Estado de Emergência, outras medidas foram aprovadas pelo Parlamento, como os projetos propostos pelo Bloco de Esquerda (BE) e pelo Partido Comunista Português (PCP) que suspenderam processos de despejo e de execução de hipotecas ${ }^{14}$. Também foi votada a suspensão de cobrança de serviços de necessidade básica, como água, energia e gás durante a pandemia. Essa possibilidade não vingou devido aos votos contrários da oposição de direita no Parlamento.

Um dia antes, entretanto, outra ação excepcional já havia sido implementada pelo governo: estado de calamidade pública e cerco sanitário no concelho de Ovar ${ }^{15}$. A cidade, com cerca de 55 mil habitantes e localizada no norte do país, no Distrito de Aveiro, registrava no dia 17 de março 30 casos e pelo menos 440 estavam em monitoramento. $\mathrm{O}$ norte do país era e segue sendo a região mais afetada pela doença, de forma que chegou a ser avaliada a possibilidade de implementação de cordão sanitário também na região metropolitana do Porto ${ }^{16}$, segundo maior adensamento populacional do país, onde vivem mais de 1,6 milhões de pessoas.

Por outro lado, o governo demonstrou desde cedo falta de preparação para uma das estratégias que a OMS tem destacado: a testagem em massa. A tática utilizada por aqui tem sido a testagem dos casos clinicamente suspeitos. Segundo a ministra Mariana Vieira da Silva, em 20 de março, o método escolhido estaria adequado, visto que o estoque existente para realização de até nove mil testes por dia estaria sobrando ${ }^{17}$. A ministra anunciou também que o governo e a comunidade científica portuguesa trabalhavam na produção de um teste nacional. Ao mesmo tempo, naquele mesmo dia, o pacote econômico disponibilizado pelo governo para apoiar a economia e as empresas já ultrapassava 9,2 bilhões de euros.

21 Em $1^{\circ}$ de abril, dia em que esse texto foi finalizado, os efeitos sanitários e econômicos da atual crise já se demonstravam intensos no país e revelavam um futuro sombrio. Do ponto de vista da saúde pública, apesar das medidas até então implementadas, ou justamente por elas, Portugal registrava mais de 8.250 casos e 187 mortes em decorrência direta do novo coronavírus. Além disso, o pico da curva epidemiológica, isto é, o período de maior criticidade de disseminação da doença, já tinha sido adiado e alongado por especialistas e autoridades nacionais. A expectativa de pico, que era em meados de abril, foi adiada para maio. Quanto às projeções de contenção da doença, já se fala sobre a possibilidade de novos surtos no inverno ${ }^{18}$.

Do ponto de vista econômico, todos os indicadores sofreram quedas imediatas, tais como os níveis de consumo privado, investimentos, importações e exportações ${ }^{19}$. 0 único que indica algum aumento é o consumo público, reflexo direto do conjunto de medidas adotadas pelo Estado. Nesse cenário, as expectativas quanto à evolução dos índices de produção e circulação nacionais estão sendo reavaliadas negativamente. 0 Banco de Portugal prevê queda de até $19,1 \%$ em exportações e até $14,9 \%$ em investimentos em 2020. Quanto ao PIB, já se trabalha com a expectativa de uma profunda recessão no futuro próximo, o que pode significar contração de até 5,7\% nesse ano. Ao mesmo tempo, espera-se a quase duplicação da taxa de desemprego, elevandose dos $6,5 \%$ do ano passado para $11,7 \%$ em 2020 . 


\section{Tempos de crises e a (des)União Europeia}

23 Deve-se dizer: é possível que estejamos testemunhando uma das maiores crises já vivenciadas na história capitalista, combinando efeitos sanitários, humanitários e econômicos comparáveis (e que podem vir a superar) a crise de 1929 e as guerras mundiais. No momento atual, a demanda efetiva e a circulação de capitais estão em queda livre em todo o mundo. A economia real, que vêm sustentando as estratégias especulativo-financeiras das últimas décadas, está em sério declínio. A China, que tem sido a âncora do mercado e da produção mundial há anos, diminuiu sua atividade industrial em pelo menos 13,5\% em janeiro e fevereiro, pior resultado das últimas três décadas ${ }^{20} \mathrm{e}$ já dá sinais claros de reorientação da sua produção para o mercado interno. o país diminuiu também suas importações de matérias primas e commodities. 0 impacto desse processo é colossal e já afeta todas as economias do planeta.

Não é à toa que Ángel Gurría, secretário-geral da Organização para a Cooperação e Desenvolvimento Económico (OCDE), veio a público defender a necessária operacionalização de um novo plano de recuperação econômica e de reformas ao estilo do que foram o Plano Marshall e o New Deal na primeira metade do século $\mathrm{XX}^{21}$. Entretanto, Gurría assinala que, para fazer face às necessidades da atual crise, dessa vez esses planos devem ter alcance global e não se restringir aos Estados Unidos, à Europa ocidental e ao Japão, tal como ocorreu no passado.

O governo português, parecendo estar atento a esses alertas e lembrando dos efeitos devastadores da última grande crise capitalista de 2008 e seus desdobramentos na zona do euro, sobretudo nos países periféricos do Sul do continente - como Portugal, Grécia, Irlanda, Chipre, Espanha -, tem exigido publicamente respostas efetivas da União Europeia. António Costa assinou conjuntamente com chefes de Estado de outros sete países (Bélgica, Eslovênia, Espanha, França, Grécia, Itália e Luxemburgo) uma carta endereçada ao Conselho Europeu, cobrando respostas imediatas, como a emissão de dívidas compartilhadas por todos os países do bloco ${ }^{22}$.

Apesar dos apelos, até o momento a UE, capitaneada pela Alemanha e outros países do Norte, segue oferecendo um cardápio de soluções requentadas que não abandonam os preceitos essenciais da austeridade neoliberal. Seguindo essa linha, o ministro das Finanças Holandês, Wopke Hoekstra, afirmou recentemente que a UE ao invés de ajudar países como a Espanha, um dos mais afetados pela pandemia no continente, deveria investigá-los. António Costa foi mais uma vez contundente, afirmando que esse tipo discurso é "repugnante" e que ameaça a UE².

Enquanto a não-resposta europeia avança, vários países do bloco e da sua zona de influência recebem toneladas de medicamentos, equipamentos médicos, testes para o Covid-19 e médicos vindos de países como China, Cuba e Rússia ${ }^{24}$. 0 presidente sérvio, Aleksandar Vucic, parece ter sintetizado uma sensação coletiva ao declarar recentemente, logo depois da Comissão Europeia ter anunciado restrições às exportações de material médico (com o objetivo de garantir suas próprias necessidades), que a solidariedade europeia é um "conto de fadas", colocando suas "esperanças na única que nos pode ajudar nesta situação difícil, a China" 25. 


\section{Notas finais} e possibilidades da fase capitalista neoliberal. Enquanto a disponibilidade do Estado chinês de intervir na economia revela opções que colocam o bem-estar coletivo à frente de demandas mercantis no decorrer da crise sanitária, as vacilações, os equívocos e os atrasos que se verificam nas medidas adotadas por Estados ocidentais - que não souberam aproveitar sua "vantagem" temporal - revelam compromissos fundantes com o mercado.

31 Portugal provavelmente não é o país que manifesta tais contradições de maneira mais aguda. Ainda assim, a atual pandemia tem sido reveladora. A forma como o Estado português agilmente se colocou como salvaguarda das empresas, lançando linhas de crédito multimilionárias e assumindo salários via fundo público, contrasta com os cortes de mais de $30 \%$ nos rendimentos de trabalhadores afetados pelo layoff simplificado e com as hesitações operacionais impostas para se fazer valer auxílios aos autônomos. Outro elemento revelador dessa contradição é a leniência do Estado em impor limites aos interesses capitalistas nesse momento. Não são poucas as denúncias de violações trabalhistas, demissões arbitrárias, especulações de preços e abusos quanto às liberdades de manifestação política dos trabalhadores nesse período. Os partidos de esquerda, como BE e PCP, têm recebido e divulgado denúncias que se avolumam durante a crise sanitária e econômica ${ }^{26}$.

Buscou-se aqui destacar as principais medidas que vem sendo desenvolvidas pelo institucional e econômico da pandemia e algumas das principais consequências no país. Ainda é cedo para determinar relações definitivas de causa e efeito entre as ações promovidas e o cenário de disseminação do vírus, tanto para o bem quanto para o mal. Entretanto, algumas hipóteses de trabalho, que se relacionam entre si, podem ser sublinhadas para futuras análises de maior fôlego.

enfrentamento à pandemia em Portugal (e na maior parte da Europa) e aquelas agressivas que se tem notícia. Revelam-se aqui diferenças tanto de cunho objetivo quanto subjetivo. Ao mesmo tempo em que as condições econômicas, tecnológicas e infraestruturais portuguesas são absolutamente incomparáveis com as chinesas, as diretrizes ideológicas que sustentam suas políticas econômicas e formas de reprodução social também são diferentes.

Não se trata aqui de uma característica restrita à Portugal, é claro, mas compartilhada em maior ou menor medida por todos os Estados tipicamente ajustados às necessidades O caso dos estivadores do Porto de Lisboa é exemplar. Os trabalhadores declararam greve em fevereiro devido a atrasos salariais, ausência de condições sanitárias e de segurança no trabalho e fraudes cometidas por uma das empresas que opera nesse terminal ${ }^{27}$. Apesar da greve, os estivadores assumiram, mesmo em condições precárias, as atividades essenciais do porto para se evitar o desabastecimento do país. Ainda assim, seguem sendo pressionados pelo governo e pelas empresas que ali operam, que parecem tentar colocar a opinião pública contra a categoria. Outro exemplo é dos trabalhadores de call-center, que decretaram greve a partir do dia 24 de março devido às condições caóticas de trabalho e a ausência de condições sanitárias mínimas para 
seguimento das atividades presenciais ${ }^{28}$. A categoria reivindica algo um tanto básico: respeito à vida.

Essas contradições que emergem das ações do Estado, que colocam os interesses do mercado à frente do bem-estar coletivo, expressam um fenômeno conhecido: a luta de classes. A história nos ensina que é justamente em crises que as contradições entre classes se agudizam, tornando o terreno de lutas ainda mais fértil. A luta de classes não para nem mesmo em tempos de crise sanitária ${ }^{29}$.

2. Dialética e simultaneamente, nota-se uma diferença não desprezível entre as formas de enfrentamento adotadas em Portugal e aquelas implementadas por seus vizinhos mais próximos, notadamente Espanha e Itália. Pode-se afirmar que, pelo menos em parte, tais diferenças se devem à força do atual governo português. António Costa foi reencaminhado ao posto de Primeiro-ministro em outubro do ano passado, depois de seu partido ter alcançado 108 dos 230 assentos na Assembleia da República, 22 a mais do que detinha na legislatura anterior ${ }^{30}$.

35 Essa estabilidade política se percebe nas elevadas taxas de aprovação registradas na última sondagem publicada no dia 27 de março, que registrou $60 \%$ de aprovação do governo, maior índice desde que Costa assumiu o posto de Primeiro-ministro em $2015^{31}$. Em outra sondagem, publicada três dias antes, verificou-se que $75 \%$ dos portugueses confiam nas respostas oferecidas pelo chefe do Executivo para o enfrentamento do Covid-19 no país. Tais números se refletem na rotina de cerca de 10 milhões de portugueses e imigrantes que vivem as últimas semanas em isolamento social. Todos os dias, pontualmente às 22 horas, ouve-se em todos os cantos do país aplausos para os trabalhadores do SNS, um reconhecimento aos funcionários que atuam na linha de frente, mas também ao sistema público de saúde que resiste e representa a melhor e mais qualificada trincheira de defesa da população contra a pandemia, apesar do sistemático sucateamento que sofre nas últimas décadas.

36 A estabilidade vivenciada em Portugal contrasta com o profundo fracionamento e hostilidade política vivenciados na Espanha e na Itália. Tratam-se de situações que já se arrastam há anos e se intensificam em momentos de crise. No caso espanhol, nota-se que houve quatro eleições para o Parlamento Nacional nos últimos quatro anos. Já na Itália, a instabilidade na alternância das alianças que governam o país tem sido uma tendência na última década, levando a uma alta rotatividade no cargo de primeiroministro. A luta política fratricida e o crescimento de setores reacionários da direita nesses países (por mais que não tenham maioria parlamentar) têm implicado diretamente em ações que prejudicam as necessárias respostas à disseminação do Covid-19.

$37 \mathrm{Na}$ Espanha, por exemplo, a extrema-direita, representada pelo Vox, organizou reuniões de milhares de pessoas, o que representa um perigo real de alavancagem de propagação do vírus e uma irresponsabilidade atroz dos organizadores ${ }^{32}$. Como diria Barão de Itararé, "de onde menos se espera, daí é que não sai nada". Além disso, as manifestações de apoio aos profissionais de saúde, que também têm sido comuns por lá, convivem com frequentes panelaços e protestos da população contra a demora na adoção de providências efetivas por parte do governo. Tal insatisfação tem sido capitaneada principalmente pelas organizações da extrema-direita. Na Itália, por sua vez, as influências de setores dessa direita obscurantista e reacionária também vêm produzindo efeitos incalculáveis. Em Milão, por exemplo, o prefeito teve que pedir desculpas públicas por incentivar, via aparelho estatal, uma campanha irresponsável 
que ignorava todas as orientações sanitárias e pregava a normalidade da vida social e econômica na cidade, obrigando os trabalhadores a arriscarem suas vidas ${ }^{33}$.

Os números falam si só: já passam dos 110 mil casos e 13,1 mil mortes, na Itália, e dos 104 mil casos e 9,3 mil mortes, na Espanha. A instabilidade política e a força de setores reacionários extremistas não explicam a totalidade do cenário em ambos os países. Incompetência, desrespeito à vida e acúmulo de anos de destruição sistemática de seus sistemas públicos de saúde, seguindo os preceitos emanados por uma suposta razão tecnocrática neoliberal, completam o quadro.

Nesse momento de crise, a estabilidade política e institucional portuguesa e sua capacidade de lidar um pouco melhor com as necessidades impostas pela pandemia (em comparação aos vizinhos próximos) podem significar a manifestação de elementos mais profundos: um acúmulo de lutas de massa organizadas em sua história recente, o que confere alguma capacidade de amortecimento do ímpeto neoliberalizante que emana do status quo político europeu e das influências reacionárias de uma extrema direita que cresce no continente.

Em suma, ao mesmo tempo em que o Estado português revela feições típicas do neoliberalismo, nota-se também um caldo social de resistência que chega a gerar efeitos na dinâmica político-institucional. Aqui estão lições importantes que merecerão análises críticas e aprofundadas no futuro. Inspirando-nos em Saramago, pode-se dizer que o futuro da humanidade enquanto humidade depende da nossa capacidade de intensificar coletivamente as resistências, não apenas à pandemia.

41 Lisboa, $1^{\circ}$ de abril de 2020.

\section{NOTES}

1. Ver mais em: <https://g1.globo.com/ciencia-e-saude/noticia/2020/01/22/china-tem-9amorte-provocada-pelo-coronavirus-ja-sao-400-casos.ghtml>.

2. Ver mais em: <http://portuguese.xinhuanet.com/2020-02/11/c_138773248.htm> e <https:// www.brasildefato.com.br/2020/03/23/china-tem-muito-a-ensinar-dizem-imigrantes-brasileirossobre-luta-contra-coronavirus>.

3. Ver mais em: <https://g1.globo.com/mundo/noticia/2020/01/23/pequim-cancela-festas-deano-novo-chines-por-conta-de-epidemia-de-coronavirus.ghtml>.

4. Ver mais em: <https://www.dn.pt/mundo/oms-medidas-tomadas-pela-china-terao-evitadocentenas-de-milhares-de-casos-11855605.html>.

5. Ver mais em: <https://www.sns.gov.pt/noticias/2020/03/11/covid-19-pandemia/>.

6. Estudos científicos de pesquisadores de vários lugares do mundo, publicados recentemente em dossiê especial da Revista Science, avaliam positivamente as medidas que têm sido adotadas pelo governo chinês para conter a pandemia. Ver mais em: <https://www.sciencemag.org/ coronavirus-research-commentary-and-news?intcmp=ghd_cov\#>. Cabe sublinhar também que, uma semana depois da declaração de pandemia, ocorreria o primeiro dia sem registro de contágio local em todo o território Chinês. Ver mais em: <https://brasil.elpais.com/ internacional/2020-03-19/o-primeiro-dia-sem-nenhum-novo-contagio-local-de-coronavirus-nachina.html>. 
7. Ver mais em: <https://sicnoticias.pt/especiais/coronavirus/2020-03-21-A-cronologia-dosnumeros-do-coronavirus-em-Portugal>.

8. Ver mais em: <https://www.portugal.gov.pt/pt/gc22/comunicacao/noticia?i=governo-adotamedidas-para-mitigar-impacte-economico-da-epidemia-covid-19-junto-das-empresas-etrabalhadores>.

9. Ver mais em: <https://www.jornaldenegocios.pt/economia/emprego/lei-laboral/detalhe/ novo-layoff-em-vigor-amanha-so-sera-prolongado-se-os-trabalhadores-anteciparem-ferias>.

10. Ver mais em: <https://www.publico.pt/2020/03/14/economia/noticia/coronavirus-apoiorecibos-verdes-438-euros-dura-seis-meses-1907722>.

11. É importante registrar que há atrasos e problemas na implementação dessas medidas, o que está dificultando que milhares de trabalhadores acessem os recursos emergenciais. Ver mais em: <https://www.publico.pt/2020/03/31/economia/noticia/ha-315-mil-recibos-verdes-risco-ficarapoio-abril-1909675>.

12. Ver mais em: <https://www.publico.pt/2020/03/26/sociedade/noticia/cerca-6500-alunosdiariamente-comer-escola-neste-periodo-encerramento-1909678>.

13. Ver mais em: <https://www.portugal.gov.pt/pt/gc22/comunicacao/documento?i=decretodo-governo-que-regulamenta-o-estado-de-emergencia-.>.

14. Ver mais em: <https://www.sabado.pt/portugal/detalhe/coronavirus-parlamento-aprovasuspensao-de-despejos-e-de-denuncias-de-contratos-de-arrendamento>.

15. Ver mais em: <https://www.publico.pt/2020/03/18/politica/noticia/coronavirus-governoestabelece-cerca-sanitaria-torno-ovar-1908216>.

16. Ver mais em: <https://www.publico.pt/2020/03/31/sociedade/noticia/autoridadesponderam-cordao-sanitario-volta-porto-1910254>.

17. Ver mais em: <https://expresso.pt/coronavirus/2020-03-20-Portugal-pode-fazer-nove-miltestes-por-dia-a-Covid-19>.

18. Ver mais em: <https://sicnoticias.pt/especiais/coronavirus/2020-03-21-Covid-19-Cientistasexplicam-porque-pode-haver-nova-vaga-no-inverno>.

19. Ver mais em: <https://www.publico.pt/2020/03/26/economia/noticia/banco-portugal-prevequeda-pib-34-ano-1909594>.

20. Ver mais em: <https://veja.abril.com.br/economia/industria-da-china-tomba-135-e-mostradevastacao-do-coronavirus/>.

21. Ver mais em: <https://www.publico.pt/2020/03/21/economia/noticia/ocde-impactopandemia-covid19-maior-piores-previsoes-1908849>.

22. Ver mais em: <https://www.dn.pt/mundo/antonio-costa-escreve-a-ue-a-defendercoronabonds-11983065.html>.

23. Ver mais em: <https://www.dn.pt/poder/discurso-de-ministro-holandes-e-repugnante-dizcosta-11992373.html>.

24. Ver mais em: <https://www.terra.com.br/noticias/o-apoio-da-china-para-a-italia-na-crisedo-coronavirus,dfe2e20b3258e0f756d996d331581f3596aaz10a.html>.

25. Ver mais em: <https://www.noticiasaominuto.com/mundo/1435337/servia-agradece-ajudaa-china-e-acusa-ue-de-falta-de-solidariedade>.

26. Ver mais em: <http://www.pcp.pt/covid-19\#webform-client-form-304968> e <https:// www.despedimentos.pt/>.

27. Ver mais em: <http://portocanal.sapo.pt/noticia/212800>.

28. Ver mais em: <https://www.publico.pt/2020/03/24/economia/noticia/trabalhadores-callcenters-greve-situacao-caotica-1909157>.

29. A recente publicação intitulada "Coronavírus e luta de classes" (2020) reúne textos oportunos sobre o tema, escritos no calor dos acontecimentos por autores como Mike Davis, Alain Badiou e David Harvey. 
30. Importa registrar que essa vitória expressiva do Partido Socialista possui um significado especial na história recente do país. Significou a vitória no interior da sociedade portuguesa, com contradições por vezes profundas, de uma solução política que ficou conhecida como "Geringonça" que vigorou de 2015 a 2019. Tal solução, resultado de um histórico acordo entre forças de esquerda e centro-esquerda, expressou a construção de obstáculos políticos nacionais contra o receituário neoliberal que vêm sendo imposto pela UE ao país (e a outros que fazem parte da "periferia" do continente) desde 2010.

31. Ver mais em: <https://expresso.pt/politica/2020-03-27-Sondagem-confirma-elevada-taxa-deaprovacao-do-Governo.-Portugueses-querem-que-Centeno-fique-como-ministro>.

32. Ver mais em: <https://www1.folha.uol.com.br/mundo/2020/03/deputado-da-ultradireita-ediagnosticado-com-coronavirus-apos-ato-do-proprio-partido-e-culpa-o-governo.shtml>.

33. Ver mais em: <https://g1.globo.com/bemestar/coronavirus/noticia/2020/03/27/prefeito-demilao-admite-erro-por-ter-apoiado-campanha-para-cidade-nao-parar-no-inicio-da-pandemiade-coronavirus-na-italia.ghtml>.

\section{ABSTRACTS}

This text is brief critic report about Portugal conjuncture in this sanitary crisis world moment and its firsts politics-institutional, economics and humanitarians' effects. This is an effort made in the heat of events and, for this, raises working hypotheses that deserve deeper future analyzes. However, there are lessons that can already be absorbed. The actions taken by the Portuguese government to deal with the pandemic reveal important similarities and differences with what happens in close neighbors, as Spain and Italy. It is also noted the gap that distances the strategies undertaken here from those recommended by the World Health Organization (WHO), inspired mainly by the Chinese case. The manifestation of this elements is intimately related with the nonstop phenomenon, in contrast, intensifies in time in crisis: class struggle.

Este texto é um breve relato crítico sobre a conjuntura em Portugal nesse momento de crise sanitária mundial e seus primeiros efeitos político-institucionais, econômicos e humanitários. É um esforço realizado no calor dos acontecimentos e, por isso mesmo, levanta hipóteses de trabalho que merecerão análises futuras mais profundas. Entretanto, há lições que já podem ser absorvidas. As ações desenvolvidas pelo governo português no enfrentamento à pandemia revelam similaridades e diferenças importantes com o que ocorre em vizinhos próximos, como Espanha e Itália. Nota-se também a lacuna que distancia as estratégias aqui empreendidas daquelas recomendadas pela Organização Mundial da Saúde (OMS), inspiradas sobretudo no caso chinês. A manifestações desses elementos está intimamente relacionada com um fenômeno que não para, ao contrário, se intensifica em momentos de crise: a luta de classes.

A partir de Portugal, on présente un bref récit critique sur la crise sanitaire mondiale et ses premiers effets politiques, institutionnels, économiques et humanitaires. Écrit au cœur des événements, et malgré les leçons qu'on peut apprendre d'avance, les hypothèses suivantes doivent être reprises dans le futur. On constate que les réactions portugaises ne sont pas les mêmes recommandées par l'OMS à partir du cas chinois, mais elles montrent si différence que similarités par rapport les cas espagnole et italien. Cette configuration est intimement liée à un phénomène en train de s'accroître en temps de crise : la lutte de classes. 
Este texto es un breve informe crítico sobre la coyuntura en Portugal en este momento de crisis de salud mundial y sus primeros efectos político-institucionales, económicos y humanitarios. Es un esfuerzo realizado en el calor de los acontecimientos y, por esa razón, plantea hipótesis de trabajo que merecerán un análisis más profundo en el futuro. Sin embargo, hay lecciones que ya pueden ser absorbidas. Las acciones tomadas por el gobierno portugués para hacer frente a la pandemia revelan importantes similitudes y diferencias con lo que sucede en los vecinos cercanos, como España e Italia. También se observa la brecha que distancia las estrategias emprendidas aquí de las recomendadas por la Organización Mundial de la Salud (OMS), inspiradas principalmente en el caso chino. La manifestación de estos elementos está estrechamente relacionada con un fenómeno que no se detiene, por el contrario, se intensifica en tiempos de crisis: la lucha de clases.

\section{INDEX}

Mots-clés: Portugal; Covid-19; Estado; luta de classes; capitalismo.

Keywords: Portugal; Covid-19; State; Class struggle

Palabras claves: Portugal; Covid-19; Estado; Lucha de clases.

Palavras-chave: Portugal; Covid-19; Estado; Luta de classes.

\section{AUTHORS}

\section{LUCAS PACHECO CAMPOS}

Professor da Universidade Federal de Juiz de Fora (UFJF), campus Governador Valadares. Doutorando em Políticas Públicas e Formação Humana pela Universidade do Estado do Rio de Janeiro (UERJ). Mestre e graduado em Administração pela Universidade Federal Fluminense (UFF). Contato: <lucas.pacheco@ufjf.edu.br>.

\section{TUÍLA LINS}

Mestra em Relações Internacional pela Universidade do Estado do Rio de Janeiro (UERJ). Graduada em Relações Internacionais pela Universidade Federal Fluminense (UFF). Contato: <tuilalins@gmail.com>. 